\title{
Estressores e estratégias de coping em uma amostra de psicólogos clínicos
}

\section{Clinical psychologists' stress sources and coping strategies}

\author{
Cristiane Élis SANZOVO \\ Myrna Elisa Chagas COELHO²
}

\begin{abstract}
Resumo
Submetido a contingências estressoras, o psicólogo clínico pode ter a qualidade do seu trabalho comprometida, acarretando conseqüências para clientes em tratamento. Este estudo teve como objetivos: avaliar níveis de stress, levantar estressores presentes no contexto de trabalho e estratégias de coping utilizadas. Participaram desta pesquisa 15 psicólogos. Aplicou-se o Inventário de Sintomas de Stress de Lipp e realizaram-se entrevistas semi-estruturadas. Os resultados indicaram que 12 participantes não apresentaram stress. Todos mencionaram estratégias de coping. O estressor mais assinalado foi "preocupação com clientes específicos"; as estratégias mais marcadas foram "tirar férias" e "praticar exercícios físicos". Concluiu-se que o uso de estratégias de coping pode relacionar-se ao fato de que muitos estressores foram percebidos no exercício da profissão, mas não têm desencadeado o processo de stress nesse grupo. Discutiu-se se o conhecimento e as habilidades adquiridas pelos psicólogos clínicos também poderiam colaborar para seu sucesso no enfrentamento dos estressores presentes em seu trabalho.
\end{abstract}

Unitermos: coping; stress ocupacional; estressores; psicólogos.

\begin{abstract}
Under stress contingencies, clinical psychologists might have their work quality compromised, what can bring consequences to clients in treatment as well. This paper objectified: to assess stress levels, to point out stress sources in the practical context, and list coping used. Fifteen psychologists participated of this research. The Lipp Stress Symptom Inventory was applied and semi-structured interviews took place. The results indicated that 12 participants didn't present stress. They all mentioned coping. The most quoted stress agent was the "concern with specific clients"; the most cited coping was to take vacation and to practice physical exercises. The research revealed that coping might be related to the fact that many stress agents were noticed during their practice, but these agents haven't unleashed the stress process in this group. It was discussed if the knowledge and the abilities acquired by the clinical psychologists could also contribute to their success facing stress agents.
\end{abstract}

Uniterms: coping; occupational stress; stress agents; psychologists.

Pode-se encontrar várias definições de stress na literatura, uma vez que existem diferentes teorias e modelos; embora entre eles não exista consenso, todos trouxeram importantes contribuições para o estudo desse tema.
Existe um modelo considerado clássico no que se refere ao stress: o modelo biológico de Selye (1956), que entende o stress como uma condição interna do organismo. Assim, diante de um evento ambiental que exija adaptação, o indivíduo emite uma resposta não

$\boldsymbol{\nabla} \mathbf{\nabla} \boldsymbol{\nabla}$

1 Faculdade de Medicina de São José do Rio Preto, Laboratório de Psicologia e Saúde. Av. Brigadeiro Faria Lima, 5416, Vila São Pedro, 15090-000, Sâo José do Rio Preto, SP, Brasil. Correspondência para/Correspondence to: C.E. SANZOVO.E-mail: <cris_sanzovo@yahoo.com.br>.

2 Universidade Estadual de Londrina, Centro de Ciências Biológicas, Curso de Psicologia. Londrina, PR, Brasil. 
específica, uma vez que qualquer evento nessas condições pode ser responsável pela sua emissão. As respostas de adaptação, segundo esse autor, se dão a partir de fases, cujo processo se denomina Síndrome de Adaptação Geral (SAG). Lipp (2003) apresenta tais fases em um modelo denominado de quadrifásico, o qual é composto de quatro fases: alerta, resistência, exaustão e quase-exaustão.

Seger (2001) traz uma definição de stress em termos de adaptação, ou seja, como ... uma resposta não específica do organismo a qualquer mudança ambiental. O organismo tenta adaptar-se, elaborar um comportamento na presença de uma situação, face à qual seus padrões habituais de referência encontram-se superados, de modo que o seu repertório pessoal de respostas comportamentais se revela insuficiente (p.214).

Para a Análise do Comportamento, o processo de stress pode ser entendido como uma mudança na relação do sujeito com o ambiente devido a alterações ambientais aversivas, o que implicará na necessidade de um novo repertório. Se o indivíduo, diante de uma alteração ambiental aversiva, não apresentar respostas comportamentais adaptativas, pode-se considerar que essa ausência de resposta se constituirá como um problema (Banaco, 2005).

Sendo assim, entende-se que o processo de stress será desencadeado e desenvolvido de maneira diferente para cada indivíduo, uma vez que a análise de cada evento como aversivo ou não dependerá de como cada pessoa aprendeu a percebê-lo. Isso quer dizer que o processo de stress está intimamente relacionado à história de vida do indivíduo, considerando que os pensamentos, sentimentos, regras e auto-regras são aprendidos no decorrer de sua vida.

Assim acredita-se que as pessoas aprendem a analisar certos eventos como ameaçadores ou não. Por exemplo, um indivíduo que viveu mais situações de controlabilidade aprenderá que é possível ter controle sobre alguns eventos do ambiente, enquanto um outro indivíduo que viveu mais freqüentemente situações de incontrolabilidade pode desenvolver uma regra de que não poderá exercer controle sobre nenhum evento em sua vida, mesmo que isso não seja verdadeiro. Se a pessoa que teve a história de controlabilidade se deparar com um evento inicialmente avaliado como incon-

228 trolável, a tendência será que, mesmo assim, tentará se comportar de alguma forma que possibilite modificá-lo (Torres \& Coelho, 2004).

Esse indivíduo, portanto, possui maior probabilidade de apresentar respostas comportamentais adaptativas diante de uma mudança ambiental do que o segundo indivíduo que não desenvolveu em seu repertório esse tipo de resposta. Considera-se que essa análise seja fundamental para a compreensão do desenvolvimento do processo de stress a partir de sua definição apresentada aqui em termos de adaptação.

\section{Fontes de stress e estressores}

Estando o stress relacionado a alterações ambientais aversivas perante as quais o indivíduo precisa apresentar respostas de adaptação, eventos que demandem algum tipo de adaptação por parte do indivíduo podem ser considerados estressores. Para Santos (1995), um único estressor não poderá levar o indivíduo ao stress, mas sim a combinação e o acúmulo de vários agentes. Zakir (2001) aponta que, quanto maior forem a intensidade, a freqüência e o tempo de duração dos estressores, maior a probabilidade de se desenvolverem reações de stress.

As fontes de stress podem ser classificadas em externas e internas. Fontes externas englobam eventos que não dependem diretamente do controle do indivíduo, isto é, mudanças inesperadas, problemas do cotidiano, acidentes ou doenças, por exemplo. Já as fontes internas estão diretamente relacionadas à pessoa e aos comportamentos privados, podendo constituir-se do padrão comportamental apresentado, nível de assertividade, vulnerabilidade, entre outros (Lipp, 1996; Lipp \& Malagris, 1998).

Para Santos (1995), os estressores são absolutos, ou seja, o evento acontece; no entanto a maneira como o indivíduo reagirá a esse evento é relativa, isto é, cada pessoa pode reagir de maneira diferente a um mesmo evento estressor. Nesse sentido, deve-se entender que cada indivíduo possui um nível de tolerância à situação estressante diferente dos demais.

Para o analista do comportamento, as variáveis envolvidas no desenvolvimento e manutenção de transtornos desadaptativos se encontram no ambiente imediato e na história ambiental do indivíduo. Portanto, 
os eventos estressores são analisados de acordo com essa história e com as contingências presentes na vida da pessoa. "A sensibilidade às contingências geradoras de stress diferencia-se de acordo com a condição genética do indivíduo e, principalmente, de sua história ambiental" (Coelho, 1998, p.11).

Assim estímulos positivamente reforçadores podem funcionar como agentes estressores tanto quanto os estímulos punitivos. Diferentes esquemas de reforçamento podem surtir efeitos estressores seja por retirada de reforçamento (extinção), por baixa densidade de gratificação (reforçamento social), entre outros (Zakir, 2001).

\section{Coping}

Segundo o modelo psicológico de Lazarus e Folkman (1984), o coping pode ser definido como um conjunto de esforços tanto cognitivos quanto comportamentais que os indivíduos empregam para lidar com as exigências específicas provenientes de uma situação de stress, exigências essas consideradas como sobrecarregadoras de seus recursos pessoais.

Esse processo pode ser entendido, então, como um conjunto de respostas comportamentais que o indivíduo, diante de uma situação de stress, emite para modificar o ambiente na tentativa de adaptar-se da melhor forma possível ao evento estressor, reduzindo ou minimizando seu caráter aversivo. Tais estratégias são aprendidas e mantidas ou não no decorrer da vida de cada indivíduo, dependendo dos esquemas de reforçamento a que cada um foi submetido durante sua história.

As estratégias de coping podem ser divididas em dois grupos distintos de acordo com sua função: coping focalizado na emoção e coping focalizado no problema (Folkman \& Lazarus, 1980). O primeiro grupo engloba estratégias cujo objetivo seja lidar com a resposta emocional desencadeada pelo evento estressor. Exemplos desse tipo de estratégia seriam fazer uma caminhada, utilizar técnicas de relaxamento, entre outros. Já as estratégias focalizadas no problema são comportamentos que promovam mudanças diretamente na situação geradora de stress com o objetivo de modificar de alguma forma o evento que está exigindo adaptação do indivíduo.
Estratégias de enfrentamento de estressores externos poderiam ser, por exemplo, fazer uso de habilidades de solução de problemas e planejamento (Seidl, Troccoli \& Zannon, 2001); desenvolvimento de repertório apropriado para obtenção de fontes de reforçamento social, como autocontrole e assertividade (Coelho, 1998); e ainda busca de suporte social, religiosidade e lazer (Seidl et al., 2001).

A importância de se desenvolver repertório de habilidades de enfrentamento é justificada por Torres e Coelho (2004), pois ... se a forma pessoal de reagir diante de acontecimentos vitais são pilares para desenvolver maior ou menor resposta ao stress, a implementação de um repertório de habilidade de enfrentamento ... levaria à minimização da aversidade e à eliminação de respostas de fuga/esquiva, resultando num aumento da percepção de controle pessoal e maiores possibilidades de enfrentamentos bem-sucedidos (p.342).

As autoras afirmam que uma das habilidades de enfrentamento mais importantes a ser aprendida é o "enxergar e lidar com as contingências", pois isso possibilitará um repertório mais adaptado e o desenvolvimento de maior tolerância aos eventos incontroláveis e imprevisíveis, características comuns dos eventos estressores. Assim esse comportamento será reforçado por suas conseqüências positivas, permitindo que as respostas aos eventos estressores sejam mais adaptativas.

\section{Stress ocupacional}

O stress ocupacional tem sido uma área bastante pesquisada por psicólogos uma vez que freqüentemente o stress tem se desenvolvido em função do trabalho exercido pelo indivíduo.

Seegers e van Elderen (1996, p.213) definem o stress ocupacional como "... o resultante da percepção entre a discordância entre as exigências da tarefa e os recursos pessoais para cumprir ditas exigências". A definição em termos de adaptação descrita anteriormente aplica-se igualmente no que se refere ao stress ocupacional. A singularidade está no fato de que as mudanças ambientais e a conseqüente necessidade de novo repertório acontecem no contexto de trabalho.

Diferentes autores têm apontado alguns estressores externos especificamente relacionados ao 
contexto de trabalho. Lazarus e Lazarus (1994) indicaram a sobrecarga de trabalho e a incerteza em relação ao futuro, entre outros. Baccaro (1990) assinalou fatores como más relações interpessoais, baixa participação na execução das tarefas, progresso na carreira, entre outros.

Stella et al. (1999 citado por Baechtold, 2002) apontam os sintomas mais característicos do stress ocupacional, o que permite perceber o quanto essa condição é prejudicial ao indivíduo e à execução adequada do seu trabalho: diminuição da eficiência e produtividade, problemas de memória, insegurança na tomada de decisões, desatenção, diminuição da capacidade de observação, imprevisibilidade na velocidade de resposta - podendo levar ao aumento de erros - entre outros.

Abreu, Stoll, Ramos, Baumgardt e Kristensen (2002) destacam algumas das características do trabalho dos profissionais da saúde mental que poderiam ser responsáveis pela tendência de eles serem mais vulneráveis ao stress ocupacional, tais como: lidar por muito tempo com pessoas que possuem transtornos mentais; ser responsável pela vida desses pacientes; dificuldade no estabelecimento de limites na interação com os pacientes; atenção constante e não recíproca aos problemas dos pacientes.

Pode-se considerar que a profissão do psicólogo clínico esteja relacionada às características acima descritas uma vez que esse profissional trabalha diretamente com o sofrimento humano.

Covolan (1996) realizou uma pesquisa sobre o stress ocupacional em psicólogos clínicos e verificou que os agentes estressores mais citados foram os problemas econômico-financeiros e os sentimentos de impotência e fracasso. A preocupação com os clientes foi considerada a fonte mais estressante, incluindo tentativa de suicídio e falecimento de clientes que estavam em atendimento.

Outro estudo feito com psicólogos clínicos dos Estados Unidos e da Inglaterra demonstrou altos níveis de stress nessa população (Rabin, Feldman \& Kaplan, 1999). Outras pesquisas levantaram possíveis fatores desencadeadores de stress em psicoterapeutas, como, por exemplo, manutenção da relação terapêutica, dúvidas profissionais, envolvimento excessivo no trabalho e esgotamento pessoal (Faber 1985), expectativas muito 230 altas e falta de gratificação (Rabin et al., 1999).
Considerando que condições estressoras estejam presentes no contexto do psicólogo clínico, o trabalho terapêutico desenvolvido por ele poderá ser afetado, ou seja, é possível que o psicólogo, submetido a contingências estressoras, tenha a qualidade do seu trabalho comprometida e, em caso de apresentar um quadro de stress, possa acarretar conseqüências também para os clientes em tratamento.

A partir dessa problemática, este estudo teve por objetivo investigar possíveis fontes estressoras mais comumente encontradas no contexto de trabalho de um grupo de psicólogos clínicos, assim como investigar as estratégias de enfrentamento (coping) que têm sido utilizadas para lidar com as contingências estressoras.

\section{Método}

\section{Participantes}

Fizeram parte do estudo 15 psicólogos clínicos, na profissão há pelo menos cinco anos, sem especificação de abordagem, convidados aleatoriamente e provenientes da cidade de Londrina, PR.

Todos os participantes eram do sexo feminino e estavam na faixa etária entre 29 e 53 anos, enquanto o tempo de experiência na área variou de 5 a 20 anos, tendo a maioria (8 sujeitos) experiência de 11 a 15 anos de profissão.

\section{Instrumentos}

Foi utilizado o Inventário de Sintomas de Stress (ISSL), (Lipp, 2000), que avalia se o indivíduo possui sintomas de stress, se tais sintomas seriam físicos ou psicológicos e a fase em que ele se encontra, uma vez que se baseia no modelo quadrifásico do stress (fase de alerta, fase de resistência, fase de quase-exaustão e fase de exaustão). Trata-se de um inventário validado utilizado para o diagnóstico de stress em adultos e jovens acima dos 15 anos de idade.

É constituído por três quadros referentes às quatro fases do stress, de maneira que o quadro um avalia a fase de alerta, o quadro dois avalia ambas as fases de resistência e quase-exaustão, e o quadro três a fase de exaustão. 
Os sintomas listados são aqueles considerados típicos de cada fase, sendo 37 de natureza física e 19 de psicológica, podendo se repetir nos três quadros, mas diferindo em intensidade e gravidade. O primeiro quadro apresenta 12 sintomas físicos e três psicológicos, em que o indivíduo deve assinalar os mais freqüentes experenciados nas últimas 24 horas. No segundo quadro (10 sintomas físicos e 5 psicológicos), devem ser assinalados os sintomas mais freqüentes sentidos na última semana. Por fim, no quadro três (12 sintomas físicos e 11 psicológicos), devem ser assinalados os sintomas mais freqüentes vividos no último mês.

Foi realizada entrevista semi-estruturada com os participantes, a partir de duas questões principais elaboradas para o fim deste estudo: (1) quais os possíveis agentes estressores que os participantes conseguiam identificar em seu dia-a-dia de trabalho e (2) quais eram as estratégias utilizadas para lidar com tais agentes.

A partir das entrevistas realizadas com os 15 participantes, elaborou-se um questionário fechado, contendo as duas questões citadas na subseção anterior, cujas alternativas foram elaboradas com base nas respostas obtidas nas entrevistas, ou seja, todos os agentes estressores e estratégias de coping levantados nas entrevistas foram listados no questionário fechado. Para isso, as entrevistas foram tabuladas a partir de uma redução fenomenológica das respostas que foram divididas nessas duas categorias: fontes estressoras e estratégias de coping.

Assim, a primeira questão pedia que fossem assinalados, dentre os itens relacionados, aqueles que o participante considerasse possíveis fontes de stress no seu trabalho como psicólogo clínico. Foram listados 27 itens, como, por exemplo: excesso de horas de trabalho, falta de intervalos durante o expediente, problemas de relacionamento entre sócios ou colegas de trabalho, problemas de horários com os pacientes ou clientes, entre outros.

A segunda questão solicitava que fossem assinaladas as estratégias utilizadas para lidar com os eventos estressores, a partir de uma lista com 35 alternativas que foram ordenadas de acordo com a classificação das estratégias de coping feita por Lipp (1984):
- Categoria A: aspectos fisiológicos (exercícios físicos, alimentação saudável, técnicas de relaxamento, entre outros);

- Categoria B: sistema de apoio (suporte social da família e de amigos, psicoterapia, religião);

- Categoria C: trabalho voluntário, recreação e hobbies;

- Categoria D: habilidades interpessoais e de controle (treinamentos e experiências de crescimento pessoal).

Uma quinta categoria, E, foi criada especialmente para abranger as estratégias específicas relacionadas à profissão de psicólogo clínico e que não poderiam ser agrupadas na classificação descrita por Lipp (1984). Como exemplos dessa categoria têm-se: concentrar-se apenas na sessão durante o atendimento; fazer supervisão dos casos, quando necessário; entre outros.

\section{Procedimentos}

O procedimento foi realizado em quatro etapas. Na primeira delas, foi feito o contato com os psicólogos clínicos escolhidos para explicar os objetivos da pesquisa e obter consentimento para participação, mediante o termo de consentimento. Tendo os psicólogos concordado com a participação, foram marcados horários específicos para aplicação do inventário e realização das entrevistas, ambos feitos no mesmo dia. A aplicação dos instrumentos foi realizada nos respectivos consultórios dos psicólogos convidados, na cidade de Londrina, PR.

A segunda etapa constou da correção dos inventários e transcrição das entrevistas. Para a correção, foram seguidos as instruções e os critérios indicados pelos autores no manual do inventário (Lipp, 2000).

A análise das entrevistas transcritas indicou uma quantidade de dados bastante numerosa e muito diversificada, de modo que se optou pela elaboração e aplicação de um questionário fechado com base nas repostas obtidas nas entrevistas. Assim, a partir do questionário, todos os participantes poderiam escolher entre todos os eventos estressores e todas as estratégias de coping levantadas nas entrevistas para assinalar aqueles considerados presentes em seu contexto de trabalho, assim como as estratégias utilizadas. Desse modo, os dados poderiam ficar mais completos. 
Teve início, então, a terceira etapa do procedimento, a qual constou da aplicação dos questionários fechados a todos os participantes. A partir de mais essa fonte de dados, foi possível categorizar as respostas de acordo com o referencial teórico apresentado neste trabalho, ou seja, fontes estressoras internas ou externas e as categorias desenvolvidas por Lipp (1984) para as estratégias de coping, citadas na subseção anterior. A quarta etapa envolveu a análise dos resultados, através da qual foram realizados os cruzamentos possíveis entre as questões levantadas e os dados obtidos através dos instrumentos utilizados.

\section{Resultados e Discussão}

Os resultados obtidos indicaram um alto número de agentes estressores no exercício da profissão percebidos pelo grupo de psicólogos clínicos. A apresentação desses resultados foi dividida de acordo com uma das classificações dos agentes estressores apresentada no referencial teórico: estressores internos e externos.

Onze sujeitos apontaram como agente estressor interno a preocupação com clientes específicos como, por exemplo, nos casos em que há risco de suicídio, clientes/pacientes controladores e/ou manipuladores, casos considerados pelos sujeitos como muito complicados e que exigem grande habilidade por parte do terapeuta (Tabela 1).

Em segundo lugar, apontado por oito sujeitos, ficou o impacto emocional sofrido pelo psicólogo clínico em casos muito graves, como, por exemplo, quando o paciente/cliente possui uma doença terminal ou foi vítima de abuso sexual, entre outros.

Ressalta-se que as fontes de stress não estão ordenadas no sentido de mais estressora para menos estressora. Esses dados indicam apenas que um determinado agente foi considerado estressor por um maior número de entrevistados, enquanto outros agentes foram considerados estressores por um menor número.

Sendo a análise de cada evento como aversivo ou não dependente da história de aprendizagem de cada indivíduo, assim como sua reação frente a tal evento, deve-se considerar que, além de possuírem histórias de vida diferentes, as pessoas estão expostas a fontes estressoras diferentes, de maneira que alguns entrevistados podem considerar um agente como estressor, enquanto outros não consideram. Isso pode ser claramente observado no relato que um dos participantes fez durante a entrevista semi-estruturada, apresentado a seguir:

Não vejo nenhum agenteestressor específico. Acho queé responsabilidade sua com seu cliente ... que não necessariamente precise ser um agente estressor... eu não vejo grandes dificuldades. De repente, outros profissionais poderiam estar tendo (Sujeito 14).

Os relatos apresentados a seguir exemplificam os dois agentes estressores internos mais apontados pelos participantes:

... acho que com relação aos atendimentos, alguns casos que são mais complicados, ... que exige muito de você.... têm uns clientes que são bem tranqüilos e têm outros quejá são mais questionadores, que questionam as coisas que você orienta, as coisas que você discute (Sujeito 7).

Tabela 1. Agentes estressores internos mencionados pelos participantes. 
... casos muito graves, por exemplo, a pessoa que está com uma doença terminal, descobriu queéportador do vírus HIV. Esse impacto que a pessoaestáem uma situação muito difícil e que você não tem como resolverisso, você só pode dar apoio emocional. ... o impacto emocional para o terapeuta é grande, porque são coisas que não estão nas suas mãos resolver (Sujeito 10).

Pode-se perceber que ambas as fontes estão relacionadas a questões emocionais, as quais também são aprendidas no decorrer da história de vida. A percepção dos sentimentos, as idéias, os valores, as regras e auto-regras são todos resultados de um processo de aprendizagem a partir do ambiente e da comunidade verbal em que se está inserido (Torres \& Coelho, 2004). Da mesma forma, a maneira como cada indivíduo irá reagir ao impacto emocional que um caso de doença terminal pode provocar dependerá da história de aprendizagem e do repertório comportamental adquirido pelo terapeuta.

Os agentes estressores externos foram apontados na entrevista semi-estruturada em maior número e estão listados na Tabela 2.

Um dos agentes estressores externos mais assinalados pelos participantes foi a instabilidade financeira (8 sujeitos), isto é, a falta de um ganho fixo. Esse agente pode ser analisado de forma diferente, pois se trata de um evento que não depende do indivíduo, isto é, a instabilidade financeira característica do trabalho em clínica não está sob o controle direto do profissional, o que caracteriza os chamados estressores externos.

As fontes estressoras mais apontadas pelos entrevistados estão de acordo com outras pesquisas realizadas sobre o tema, as quais indicaram como agentes estressores a sobrecarga de trabalho (Covolan, 1996; Faber, 1985; Lazarus \& Lazarus, 1994), a preocupação excessiva com clientes (Covolan, 1996), a falta de gratificação (Rabin et al., 1999) e os problemas econômico-financeiros (Covolan, 1996).

Os resultados obtidos a partir do ISSL indicaram que dentre os 15 psicólogos entrevistados, apenas três apresentaram stress, embora tenham sido levantados diversos agentes estressores considerados importantes e intervenientes no exercício da profissão.

Segundo Zakir (2001), as dimensões da reação de stress não são, necessariamente, proporcionais às dimensões dos agentes estressores. Havendo muitas fontes estressoras em um ambiente, a probabilidade do

Tabela 2. Agentes estressores externos mencionados pelos participantes.

\begin{tabular}{|c|c|}
\hline Agentes mencionados como estressores no trabalho do psicólogo clínico & Assinalado por (sujeitos) \\
\hline Excesso de horas de trabalho & 8 \\
\hline Instabilidade financeira & 8 \\
\hline Falta de intervalos durante o expediente & 7 \\
\hline Atraso no pagamento & 7 \\
\hline Dificuldade de familiares colaborarem com o tratamento do cliente/paciente quando necessário & 7 \\
\hline Pacientes/clientes que faltam sem avisar previamente & 6 \\
\hline Resistência natural ao tratamento & 5 \\
\hline Clientes/pacientes e familiares que exigem tempo fora da sessão & 5 \\
\hline Mercado competitivo & 5 \\
\hline Perceber que não está em condições de trabalhar e não poder tirar férias & 5 \\
\hline Problemas de horário com os pacientes/clientes & 4 \\
\hline Atraso de pacientes/clientes & 4 \\
\hline Dificuldade de acesso a médicos para trabalho em conjunto & 4 \\
\hline Pacientes/clientes que invadem a vida pessoal do terapeuta & 3 \\
\hline Barulho da rua & 3 \\
\hline Atividade que demandam muito tempo & 2 \\
\hline Pacientes/clientes que confundem o trabalho do psicólogo com outros profissionais & 2 \\
\hline Falta de outros colegas no mesmo ambiente de trabalho & 1 \\
\hline
\end{tabular}


aparecimento de reações de stress aumenta, principalmente se a intensidade e a freqüência dessas fontes forem altas. No entanto, devido à singularidade da história de vida e aprendizagem de cada um, é impossível prever se, trabalhando em um ambiente onde existam muitos agentes estressores, o profissional irá apresentar ou não reações de stress. Essa questão pode ser observada no relato de um entrevistado.

... eu tenho mais dificuldade em estar administrando algumas situações de stress do que, de repente, a minha sócia. Pela história de cada um.... Eu tive que ir aprendendo a melhorar minha qualidade de vida e a lidar de uma forma que a situação não precise ser tão desgastante (Sujeito 14).

Os resultados indicaram ainda que os entrevistados afirmaram a necessidade de algum tipo de estratégia de coping, citando vários exemplos utilizados em seu dia-a-dia no trabalho. Foram muitas as estratégias levantadas, de maneira que serão apresentadas divididas nas categorias A, B, C, D e E já citadas anteriormente.

Dentro da categoria A (aspectos fisiológicos), a estratégia mais assinalada pelos participantes foi a prática de algum tipo de exercício físico (12 sujeitos), como, por exemplo, academia, caminhada, alongamento, entre outros. Em segundo lugar, apareceu a alimentação saudável (11 sujeitos), seguida do hábito de dormir bem (10 sujeitos). Em quarto lugar ficou o respeito pelo relógio biológico do corpo (8 sujeitos) e, por último, os exercícios de relaxamento (5 sujeitos).

Na categoria B (sistema de apoio), a estratégia mais assinalada foi conversar com pessoas de confiança (11 sujeitos). Em segundo lugar, ficou fazer orações e ir à igreja (9 sujeitos) e, em terceiro, fazer terapia ou análise (7 sujeitos).

Em relação à categoria C (trabalho voluntário, recreação e hobbies), a estratégia mais marcada pelos participantes foi ter vida social (11 sujeitos), ou seja, desenvolver atividades como conversar com amigos, namorar, sair para dançar, viajar, entre outras. Em segundo lugar, ficaram duas estratégias assinaladas por nove sujeitos cada uma: fazer trabalhos manuais como, por exemplo, artesanato, bordado, pintura; e passar tempo com a família. Em terceiro lugar, ficaram novamente duas estratégias, marcadas por oito participantes cada uma: ter um hobby, como, por exemplo, dança, fotografia etc.; e ter o hábito de leitura.

Tabela 3. Estratégias de coping da categoria E (Estratégias próprias da profissão de psicólogo clínico).

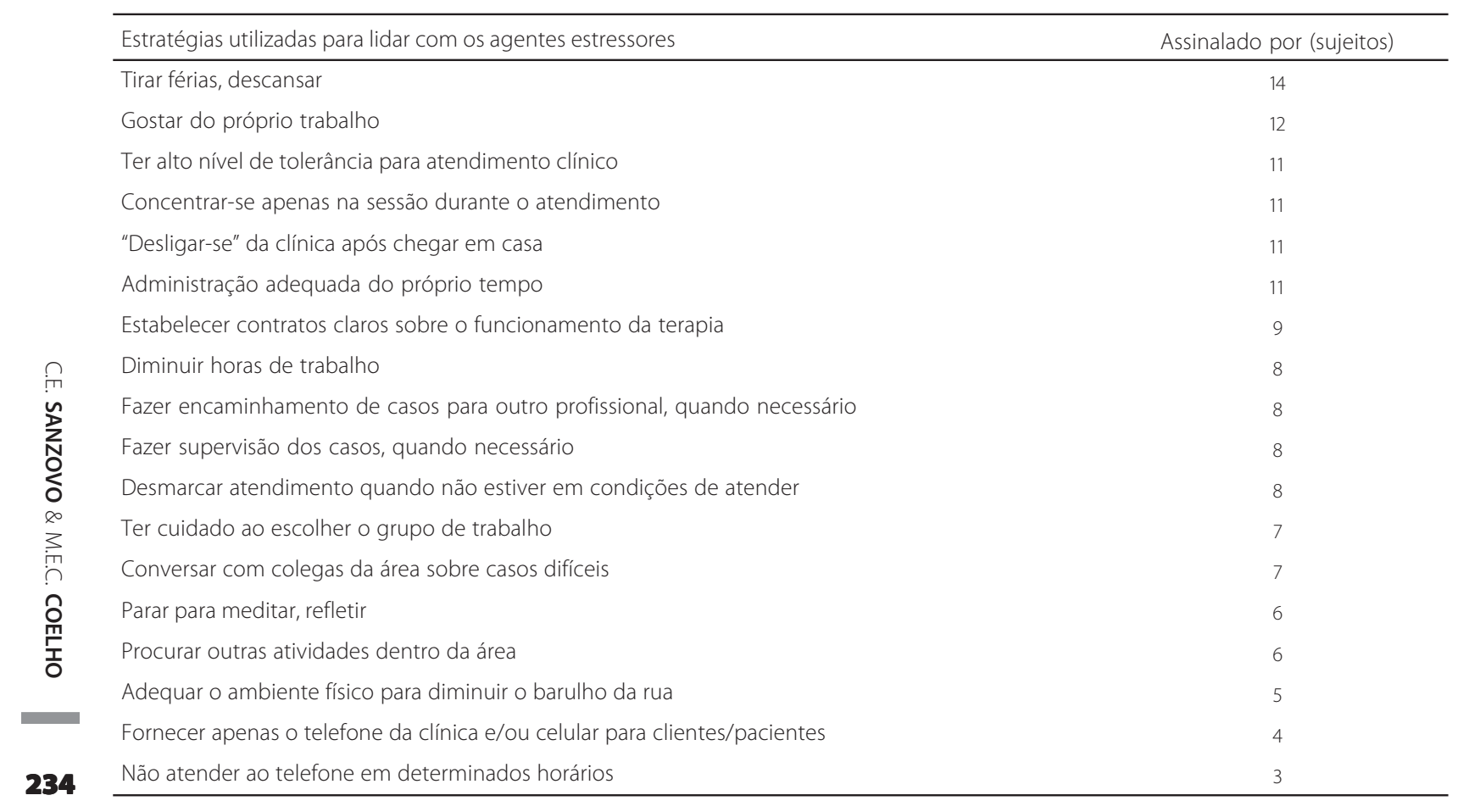


Entre as estratégias da categoria D (habilidades interpessoais e de controle), a mais assinalada foi ter senso de humor (10 sujeitos), seguida de estudar e pesquisar (9 sujeitos) e ser uma pessoa otimista (9 sujeitos).

A categoria E, ou seja, as estratégias próprias da profissão de psicólogo clínico, está representada na Tabela 3 e conforme observa-se, a fonte estressora mais assinalada foi tirar férias/descansar (14 sujeitos), seguida de gostar do próprio trabalho (12 sujeitos), ou seja, obter reforçadores a partir do contexto de trabalho.

A partir dos resultados obtidos em relação à incidência de stress nesse grupo e esse grande número de estratégias de coping citadas pelos entrevistados como parte de seu repertório comportamental, tanto na vida pessoal quanto no trabalho, levantou-se a hipótese da relação entre o uso de estratégias de coping e o não aparecimento de reações de stress.

Sendo as estratégias de coping "... uma resposta comportamental ao stress com a finalidade de reduzir suas qualidades aversivas" e sua utilização dependente do"repertório individual e de experiências tipicamente reforçadas" (Coelho, 1998, p.12), pode-se considerar que a população pesquisada está tendo sucesso em usá-las.

Essa hipótese está de acordo com outras pesquisas da área, que também tiveram como objetivo investigar estratégias de coping utilizadas no ambiente de trabalho. Ribeiro (1999), em seu estudo com psicólogos de serviços básicos e ambulatoriais de saúde pública, conclui que seus sujeitos, utilizando estratégias de coping de confronto no trabalho, apresentaram tendência à melhor qualidade de saúde e bem-estar. Guido (2003), em sua pesquisa com enfermeiros de centro cirúrgico e recuperação anestésica, concluiu que essa é uma população estressada, mas que possui algumas estratégias que proporcionam ajuda no cumprimento de suas funções.

As várias estratégias específicas da profissão de psicólogo clínico indicadas também corroboram apontamentos da literatura. Alguns exemplos podem ser citados, como as estratégias de "administrar adequadamente o próprio tempo","estabelecer contratos claros sobre o funcionamento da terapia", "diminuir horas de trabalho", entre outras que consistem no uso de habilidades de resolução de problemas e planejamento, conforme indica Seidl et al. (2001).
Zakir (2001) afirma que a característica de alguns estímulos de desencadear reações de stress está relacionada com outras propriedades dos estímulos como, por exemplo, a motivacional. "Quanto menos positivamente reforçadoras forem as atividades ocupacionais, mais peso terá a sobrecarga de trabalho, inclusive em relação ao stress" (Zakir, 2001, p.15).

A relação da sobrecarga de trabalho, citada pelos entrevistados como um agente estressor, com o aparecimento do stress implica considerar a propriedade altamente reforçadora das tarefas envolvidas no trabaIho, assim como a existência de outros reforçadores arbitrários como prestígio, reconhecimento pessoal, entre outros (Lipp, 1996).

Em relação a isso, os participantes apontaram como estratégia para lidar com os agentes estressores "gostar do próprio trabalho", ou seja, exercer atividades profissionais que sejam reforçadoras por si só. Lipp (1996) afirma que o prazer também constitui um fator que pode estar relacionado ao stress no trabalho. Portanto essa é mais uma variável a ser considerada nas diferenças individuais nas reações de stress diante de um agente estressor como o excesso de trabalho, pois esse pode desencadear uma reação de stress em alguns profissionais e não apresentar nenhum efeito negativo para outros.

Algumas falas dos entrevistados podem ilustrar essa questão:

Amo demais o meu trabalho e isso faz com que eu me sinta muito bem (Sujeito 15).

... fiz uma diferenciação nas minhas atividades.... peguei o horário que era de atendimento de cliente para uma outra atividade, o grupo de supervisão que eu monteina clínica, queé... mais fácil para eu fazer e mais prazerosa. se comparar um caso muito difícil e essa atividade, eu canso menos com isso (Sujeito 10).

Em relação aos três participantes que apresentaram stress, todos na fase de resistência, é importante afirmar que não se tem conhecimento de quais outras contingências podem estar envolvidas nesse quadro. Também não é possível afirmar se o quadro indicado pelo ISSL está relacionado a eventos estressores presentes no trabalho ou na vida pessoal. Essa questão não foi abrangida nos objetivos deste estudo, mas pode vir a ser uma fonte de investigação para futuras pesquisas. 
Os entrevistados que apresentam stress citaram alguns efeitos sentidos diante de situações estressantes no trabalho que corroboram os exemplos levantados pela literatura (Stella et al., 1999 citado por Baechtold, 2002). Esses relatos estão apresentados a seguir:

Eu começo a não lembrar de algumas coisas. Por exemplo, eu saio daqui para ir até a secretária e não lembro o que estou fazendo. Opaciente me fala as coisas e eu não lembro o que ele acabou de falar (Sujeito 13).

... acho que esse stress interfere no seu próprio raciocínio e desempenho. ... aumenta a insônia, ... E aí a baixa da imunidade ... que é resposta ao stress mesmo (Sujeito 14).

Um entrevistado que não apresentou stress na época da pesquisa relatou um exemplo interessante dos efeitos de uma situação estressora em um outro período de sua vida:

Por exemplo, um caso que eu atendi há um ano e meio atrás, ... um caso que a pessoa corria algum risco de suicídio, estava sob a minha responsabilidade. Aífoi um período em que eu não dormia direito, meu cabelo começou a cair. Eu tinha vários sintomas que eu achava quefosse de stress... aquilo estava me deixando bastante preocupada o tempo inteiro e era uma coisa que eu não tinha descanso. Era como se eu tivesse em estado de suspense o tempo inteiro (Sujeito 11).

A análise dos resultados também permite levantar uma outra hipótese referente ao desenvolvimento ou não de stress nessa população, que seria a relação da própria profissão de psicólogo clínico para lidar com o controle do stress. Sabe-se que esse tema faz parte do trabalho desses profissionais, uma vez que o stress vem se tornando condição cada vez mais freqüente entre a população. Segundo a Organização Mundial de Saúde e o Banco Mundial, estima-se que 15\% das pessoas no mundo todo sofram de distúrbios relacionados ao stress (Lipp, 2004).

A hipótese levantada, portanto, está relacionada à importância da informação e conhecimento acerca da aplicação do controle do stress. Se tal aplicação está incluída no trabalho terapêutico, entende-se que esses profissionais tenham desenvolvido, durante sua formação acadêmica e no decorrer dos anos de profissão, certas habilidades necessárias para lidar com a situação também em suas próprias vidas, especialmente nesse grupo de entrevistados que já possui alguns anos de 236 experiência na área.
Os resultados obtidos parecem demonstrar que o conhecimento acerca do controle do stress existe. Tem-se como exemplo um procedimento de treino de controle de stress descrito por Lipp e Malagris (1998) que envolve a análise funcional das contingências estressoras e intervenção direta baseada nos chamados quatro pilares do controle do stress: relaxamento, alimentação, exercício físico e modificações na área cognitiva - esse último entendido pela Análise do Comportamento como modificação e elaboração de novas regras mais adaptativas. As estratégias de coping apontadas pelos participantes incluíram os quatro pilares do controle do stress, como pode ser observado nos relatos a seguir:

... eu tenho sim a minha administração da minha qualidade de vida.... sou uma pessoa assim muito voltada para uma alimentação saudável, eu me exercito diariamente (Sujeito 6).

Ter sua própria análise, estudo, atividades extras, ter qualidade de vida fora, lazer, namorar, passear, fazer atividade física (Sujeito 5).

Segundo Torres e Coelho (2004), uma importante habilidade no manejo do stress é estar sempre sensível às contingências de maneira que seja possível perceber as mudanças significativas no ambiente que poderiam vir a demandar algum tipo de adaptação. Dessa forma, o indivíduo poderá adquirir um repertório comportamental mais adaptado e desenvolver maior tolerância aos eventos incontroláveis e imprevisíveis, como normalmente são os eventos estressores.

O trabalho do psicólogo clínico exige que ele seja capaz de identificar contingências presentes na vida dos clientes, ou seja, é necessário para a própria eficiência de seu trabalho que ele desenvolva a habilidade de estar sensível às contingências e ter repertório comportamental para lidar com elas.

Além de conhecimento teórico, esse profissional precisa ter desenvolvidas em seu repertório habilidades sociais (assertividade, empatia etc.), de resolução de problemas, de enfrentamento, de autocontrole, entre outras. Por essa razão levanta-se a hipótese de que essa seja uma população privilegiada em termos de conhecimento, informação e habilidades necessárias ao controle do stress, e que isso fica demonstrado, nesse grupo, pelos baixos níveis de stress encontrados.

É importante que se apontem também as limitações deste estudo especialmente por envolver 
uma população pequena, o que dificulta a generalização das hipóteses encontradas. Outras questões poderiam ter sido abordadas, como, por exemplo, quais agentes seriam mais estressores, ou quais estratégias de coping seriam mais efetivas. No entanto considera-se que os dados obtidos sejam relevantes para o desenvolvimento de mais pesquisas com essa população específica para que outras discussões mais abrangentes possam ser realizadas.

\section{Considerações Finais}

A importância do uso de estratégias de coping demonstrada pelos participantes pode estar relacionada ao fato de que tantos agentes estressores sejam percebidos no dia-a-dia da profissão, mas que não sejam analisados como ameaçadores e não desencadeiem o processo de stress nesse grupo. Da mesma forma, o conhecimento e as habilidades adquiridas pelos psicólogos clínicos também podem colaborar para que apresentem mais sucesso no enfrentamento dos agentes estressores presentes em sua vida profissional.

Nesse sentido, observam-se ainda benefícios para o exercício da profissão clínica, pois o cliente também é favorecido. É fundamental que o psicólogo seja capaz de desenvolver técnicas de autocuidado satisfatórias para que também seja capaz de fazer intervenções apropriadas, não somente por estar em melhores condições físicas e emocionais, como também por ter em seu repertório comportamentos que pretende ajudar o cliente a desenvolver.

Segundo Lipp e Malagris (1998), não é possível eliminar o stress da vida das pessoas, mas existem muitos meios para evitar que ele se torne excessivo e, conseqüentemente, acarrete tantos outros problemas para os indivíduos. Por essa razão, ressalta-se a importância do conhecimento acerca desde processo, de suas fases e de suas manifestações para que seja possível controlar seus efeitos negativos.

A capacidade do ser humano em se adaptar a situações adversas, seja através de comportamentos aprendidos por regras ou diretamente pela exposição às contingências, possibilita meios para evitar e/ou enfrentar situações estressoras. Essa capacidade somada aos benefícios proporcionados pela informação permite considerar importantes avanços em direção à melhora da qualidade de vida das pessoas.

Sendo assim, defende-se a importância de pesquisas relacionadas ao stress de maneira a identificar cada vez mais situações que possam gerar conseqüências negativas para o ser humano, e todas as implicações referentes à questão, não apenas no trabalho, mas em todas as áreas de sua vida.

\section{Referências}

Abreu, K. L., Stoll, I., Ramos, L. S., Baumgardt, R. A., \& Kristensen, C. H. (2002). Stress Ocupacional e Síndrome de Burnout no exercício profissional da Psicologia. Psicologia: Ciência e Profissão, 22 (2), 22-29.

Baccaro, A. (1990). Vencendo o stress: como detectá-lo esuperá-lo (2a. ed.). Petrópolis: Vozes.

Baechtold, A. P. (2002). Qualidade de vida, fontes internas e sintomas de stress em uma amostra de costureiras. Dissertação de mestrado não-publicada, Pontifícia Universidade Católica de Campinas.

Banaco, R. (2005, Agosto). Stress e terapia comportamental. Trabalho apresentado no XIV Encontro Brasileiro de Psicoterapia e Medicina Comportamental. Campinas, SP.

Coelho, M. E. C. (1998). Stress, eventos vitais e coping sob enfoque analítico-comportamental. Monografia não-publicada, Universidade Estadual de Londrina.

Covolan, M. A. (1996). Stress ocupacional do psicólogo clínico: seus sintomas, suas fontes e as estratégias utilizadas para controlá-lo. In M. E. N. Lipp (Ed.), Pesquisas sobre stress no Brasil: saúde, ocupações e grupos de risco (pp.225-240). Campinas: Papirus.

Faber, B. (1985). Clinical psychologists' perceptions of psychotherapeutic work. Clinical Psychologist 38 (1), 10-13.

Folkman, S., \& Lazarus, R. S. (1980). An analysis of coping in a middle-aged community sample. Journal of Health and Social Behavior, 21 (3), 219-239

Guido, L. A. (2003). Stress e coping entre enfermeiros de centro cirúrgico e recuperação anestésica. Tese de doutorado não-publicada, Universidade Estadual de São Paulo.

Lazarus, R. S., \& Folkman, S. (1984). Stress, apraisal and coping. New York: Springer.

Lazarus, R. S., \& Lazarus, B. N. (1994). Passion and reason: making sense of our emotions. New York: Oxford University Press.

Lipp, M. E. N. (1984). Stress e suas implicações. Estudos de Psicologia 1 (1), 3-19.

Lipp, M. E. N. (1996). Stress: conceitos básicos. In M. E. N. Lipp (Ed.), Pesquisas sobreo stress no Brasil: saúde, ocupações e grupos de risco (pp.17-29). Campinas: Papirus.

Lipp, M. E. N. (2000). Manual do inventário de sintomas de stress para adultos. São Paulo: Casa do Psicólogo. 
Lipp, M. E. N. (2003). O modelo quadrifásico do stress. In M. E. N. Lipp (Ed.), Mecanismos neuropsicofisiológicos do stress: teoria e aplicações clínicas (pp.17-22). São Paulo: Casa do Psicólogo.

Lipp, M. E. N. (2004). Prefácio. In M. E. N. Lipp (Ed.), O stress no Brasil: pesquisas avançadas (pp.11-13). Campinas: Papirus.

Lipp, M. E. N., \& Malagris, L. N. (1998). Manejo do stress. In B. Rangé (Ed.), Psicoterapia comportamental e cognitiva: pesquisa, prática, aplicações e problemas (pp.279-291) Campinas: Editorial Psy.

Rabin, S., Feldman, D., \& Kaplan, Z. (1999). Stress and intervention strategies in mental health professionals. British Journal of Medical Psychology, 72 (2), 159-169.

Ribeiro, D.P. S. A. (1999). Estratégias de"Coping"em psicólogos de serviços básicos e ambulatoriais de saúde pública. Dissertação de mestrado não-publicada, Universidade Estadual de São Paulo.

Santos, O. A. (1995). Ninguém morre de trabalhar: o mito do stress (3a. ed.) São Paulo: Textonovo.

Seegers, G., \& van Elderen, T. (1996). Examining a model of stress reactions of bank directors. European Journal of Psychological Assessment 12 (3), 212-223.
Seger, L. (2001). O stress e seus efeitos no profissional, na equipe e no paciente odontológico. In M. L. Marinho \& V. E. Caballo (Eds.), Psicologia clínica e da saúde (pp.213-223). Londrina: Ed. UEL.

Seidl, E. M. F., Troccoli, B. T., \& Zannon, C. M. L. C. (2001). Análise fatorial de uma medida de estratégias de enfrentamento. Psicologia: Teoria e Pesquisa, 17 (3), 225-234.

Selye, H. (1956). The stress of life. Nova York: McGraw-Hill.

Torres, N., \& Coelho, M. E. C. (2004). O stress, o transtorno do pânico e a psicoterapia: a pessoa e sua vida. In M. Z. Brandão et al. (Eds.), Sobre comportamento e cognição. Contingências e metacontingências: contextos sócios-verbais e o comportamento do terapeuta (Vol. 13, pp.339-344). Santo André: ESETec.

Zakir, N. S. (2001). Enfrentamento e percepção de controlabilidade pessoal e situacional nas reações de stress. Tese de doutorado não-publicada, Pontifícia Universidade Católica de Campinas.

Recebido em: 11/4/2006

Versão final reapresentada em: 19/9/2006

Aprovado em: 24/10/2006 